\title{
Defects of T-cell effector function and post-thymic maturation in X-linked hyper-IgM syndrome
}

\author{
Ashish Jain, ${ }^{1}$ T. Prescott Atkinson, ${ }^{2}$ Peter E. Lipsky, ${ }^{3}$ Jay E. Slater, ${ }^{4}$ David L. Nelson, ${ }^{5}$ \\ and Warren Strober ${ }^{1}$
}

\begin{abstract}
${ }^{1}$ Mucosal Immunity Section, Laboratory of Clinical Investigation, National Institute of Allergy and Infectious Diseases/National Institutes of Health, Bethesda, Maryland 20892, USA

${ }^{2}$ Department of Pediatrics, University of Alabama-Birmingham, Birmingham, Alabama 35294, USA

${ }^{3}$ Department of Rheumatology and Immunology, University of Texas-Southwestern, Dallas, Texas 75235, USA

${ }^{4}$ Department of Pediatrics, Children's National Medical Center, Washington, DC 20010, USA

${ }^{5}$ Immunophysiology Section, Metabolism Branch, National Cancer Institute/National Institutes of Health, Bethesda, Maryland 20892, USA
\end{abstract}

Address correspondence to: Warren Strober, Room 11N238, Building 10, National Institutes of Health, Bethesda, Maryland 20892, USA. Phone: (301) 496-6810; Fax: (301) 402-2240; E-mail: wstrober@niaid.nih.gov

Received for publication November 24, 1998, and accepted in revised form March 15, 1999. X-linked hyper-IgM syndrome (XHIM) results from mutations in the gene encoding for CD40 ligand
(CD154). Patients with the syndrome suffer from infections with opportunistic pathogens such as Cryp-
tosporidium and Pneumocystis carinii. In this study, we demonstrate that activated T cells from patients
with XHIM produce markedly reduced levels of IFN- $\gamma$, fail to induce antigen-presenting cells to syn-
thesize IL-12, and induce greatly reduced levels of TNF- $\alpha$. In addition, we show that the patients' circu-
lating T lymphocytes of both the CD4 $4^{+}$and CD8 ${ }^{+}$subsets contain a markedly reduced antigen-primed
population, as determined by CD $45 \mathrm{RO}$ expression. Finally, we demonstrate that the defects in antigen
priming are likely due to the lack of CD154 expression and insufficient costimulation of T cells by
CD80/CD86 interactions. Taken together, this study offers a basis for the increased susceptibility of
patients with XHIM to certain opportunistic infections.

J. Clin. Invest. 103:1151-1158 (1999).

\section{Introduction}

$\mathrm{X}$-linked hyper-IgM syndrome (XHIM) is an immunodeficiency disorder characterized by low levels of IgG, IgE, and $\operatorname{IgA}$, but normal-to-elevated levels of $\operatorname{IgM}(1,2)$. The syndrome is caused by mutations in the gene encoding CD40 ligand (CD154), a molecule expressed on the surface of activated $\mathrm{CD}^{+} \mathrm{T}$ cells that interacts with CD40 on the surface of $\mathrm{B}$ cells to provide an essential signal for B-cell proliferation and differentiation (3-7). As a consequence, patients with XHIM, as well as CD154 knockout mice, exhibit profoundly depressed B-cell activation, fail to form germinal centers, do not generate IgG-, IgA-, and IgE-producing B cells, and mount poor primary and secondary antibody responses (8-10).

Patients with XHIM are unlike other patients with defects in immunoglobulin production (e.g., Bruton's agammaglobulinemia) in that they frequently suffer from infection with opportunistic pathogens such as Cryptosporidium and Pneumocystis carinii, despite treatment with $\gamma$-globulin $(2,11)$. A possible basis for this clinical predisposition comes from CD154 knockout mice, which also manifest increased susceptibility to certain infectious agents. In such mice, it has been shown that deficient CD154 expression on activated T cells leads to impaired IL-12 production and reduced Th1 Tcell responses $(12,13)$. Furthermore, deficient CD154 expression in mice is associated with susceptibility to Leishmania infection, which is reversed by pretreatment with IL-12 (13). Thus, the CD154 knockout model suggests that opportunistic infections in patients with
XHIM can be attributed to defective IL-12 responses and Th1 T-cell differentiation. However, this possibility has not been explored in patients with XHIM.

In this report, we demonstrate that activated $T$ cells from patients with XHIM produce markedly reduced levels of IFN- $\gamma$, fail to induce antigen-presenting cells (APCs) to synthesize IL-12, and induce greatly reduced levels of TNF- $\alpha$. We further demonstrate that patients with XHIM have a defect in post-thymic maturation of $\mathrm{CD}^{+}$and $\mathrm{CD}^{+} \mathrm{T}$ cells characterized by a diminished capacity to generate mature $\mathrm{CD} 45 \mathrm{RO}^{+} \mathrm{T}$ cells. As shown here, this is likely due to the lack of CD154 expression and insufficient costimulation of T cells by CD80/CD86 interactions. These results imply that the increased susceptibility of patients with XHIM is in fact caused by defective induction of IL-12, leading to reduced elaboration of mature Th1 T cells.

\section{Methods}

Patients and protocols. Six patients with XHIM were studied at the Clinical Center, National Institute of Allergy and Infectious Diseases/National Institutes of Health (NIAID/NIH) (protocol no. 89-1-0158). The diagnosis was established in each patient by medical and family history, immunoglobulin profile, and sequencing of the CD154 gene. Unaffected family members of patients, other normal volunteers, and immunologically normal individuals on other NIH protocols served as controls. The Institutional Review Board of NIAID approved the open protocol, and informed consent was obtained from all patients or their parents before enrollment in the study.

CD40 ligand gene analysis. DNA and total RNA were extracted 


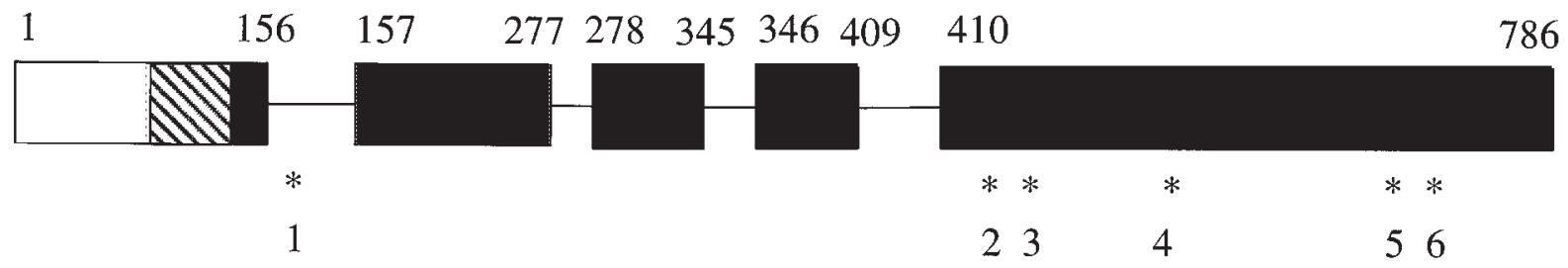
Patient 1
Splice donor site mutation
Patient 2
Insertion in coding sequence
Patient 3
6-bp in-frame deletion
Patients 4, 5, 6
Point mutations resulting in aa substitution

\section{Extracellular region \\ \$ransmembrane region \\ Intracellular region}

\section{Figure 1}

Structure of the human CD40L gene, illustrating the nature and location of the mutations with respect to the extracellular, transmembrane, and intracellular regions (21). Numbering starts from A of the initiator (ATG) codon.

from activated lymphocytes using standard methods. cDNA was obtained from RNA by RT-PCR using CD154-specific primers. PCR of genomic DNA was performed with primers flanking each exon using primers and PCR cycling conditions described previously (14-16). The PCR products were purified and cycle sequenced at both the $5^{\prime}$ and $3^{\prime}$ ends using dye terminator dideoxynucleotides.

Flow cytometry. Specimens of peripheral blood were obtained during routine patient clinic visits and were handled according to established clinical guidelines. The specimens were stained by flow cytometry with the whole-blood lysis technique and analyzed with a FACScan (Becton Dickinson Immunocytometry Systems, San Jose, California, USA) with Lysis II software by methods described previously (17). The monoclonal antibodies used included anti-CD3ع (Leu-4) and anti-CD4 (Leu-3) (Becton Dickinson Immunocytometry Systems), anti-CD45RO (UCHL-1) (DAKO Corp., Carpinteria, California, USA), and anti-CD8 (Leu-2a) and anti-CD45RA (Alb11) (Gentrack, Plymouth Meeting, Pennsylvania, USA). Irrelevant antibodies of the IgG1, IgG2a, IgG2b subclasses were used to ascertain background staining. To calculate absolute numbers of each lymphocyte subgroup, the percentage of cells staining positive was multiplied by the absolute count of peripheral blood lymphocytes, as determined by Coulter Counter (Coulter Electronics Ltd., Hialeah, Florida, USA), followed by a differential leukocyte count in a blood sample obtained simultaneously.
Cell preparation and culture conditions. PBMCs were obtained from patients and healthy adult volunteers by centrifugation of heparinized blood over Ficoll-Hypaque density gradient lymphocyte separation medium (Pharmacia Biotech, Inc., Piscataway, New Jersey, USA), using standard techniques (18). All patients had a complete blood count with differential performed on the same day that the cytokine studies were performed. Their monocyte counts were comparable to those seen in the normal volunteers, and no adjustments were made in PBMCs. To measure IL-12 production, $2 \times 10^{6} \mathrm{PBMCs}$ were cultured in $1 \mathrm{ml}$ of RPMI- 1640 complete medium for $36 \mathrm{~h}$. For anti-CD3E stimulation, 64.1 antibody (gift of Bristol-Myers Squibb, Princeton, New Jersey, USA) was first dissolved in carbonate buffer ( $\mathrm{pH} 9.6$ ) at a concentration of $2.5 \mu \mathrm{g} / \mathrm{ml}$ and aliquoted into 24 -well tissue culture plates at $250 \mu \mathrm{l} /$ well. After a two-hour incubation at $37^{\circ} \mathrm{C}$, the plates were washed twice in sterile PBS. For anti-CD3ع, OKT3 antibody (gift of Ortho Biotech, Somerset, New Jersey, USA) was first dissolved in carbonate buffer at a concentration of $10 \mu \mathrm{g} / \mathrm{ml}$ and aliquoted into 24-well plates at $250 \mu \mathrm{l} /$ well. After overnight incubation at $4^{\circ} \mathrm{C}$, the plates were washed twice in sterile PBS. Cell suspensions were then added. Human IFN- $\gamma$ was used at $1,000 \mathrm{U} / \mathrm{ml}$, Staphylococcus aureus, Cowan's strain I (SAC) (Pansorbin cells; Calbiochem Corp., La Jolla, California, USA) at 1:10,000 (wt/vol), LPS from Escherichia coli 01127:B8 (Sigma Chemical Co., St. Louis, Missouri, USA) at $1 \mu \mathrm{g} / \mathrm{ml}$, phytohemagglutinin

Table 1

Laboratory and clinical findings in six patients with XHIM

\begin{tabular}{|c|c|c|c|c|c|c|c|c|c|c|}
\hline \multirow[b]{2}{*}{ Patient } & \multirow[b]{2}{*}{ Age } & \multicolumn{3}{|c|}{$\begin{array}{c}\mathrm{CD}^{+\mathrm{A}} \\
\text { cells } / \mathrm{mm}^{3}(\%)\end{array}$} & \multicolumn{3}{|c|}{$\begin{array}{c}\mathrm{CD}^{+\mathrm{A}} \\
\text { cells } / \mathrm{mm}^{3}(\%)\end{array}$} & \multicolumn{3}{|c|}{ Clinical findings } \\
\hline & & Total & $\begin{array}{c}\text { CD45RO'B } \\
203-524(23-74)\end{array}$ & $\begin{array}{c}C D 45 R^{+B} \\
57-608(8-46)\end{array}$ & Total & $\begin{array}{c}\mathrm{CD} 45 \mathrm{RO}^{+\mathrm{B}} \\
28-240(7-42)\end{array}$ & $\begin{array}{c}C D 45 R A^{+B} \\
50-438(13-68)\end{array}$ & Neutropenia & $\begin{array}{c}\text { P. carinii } \\
\text { pneumonia }\end{array}$ & Other \\
\hline 1 & 7 & 1,986 & $240(12.1)$ & $1,457(73.7)$ & 696 & $35(5)$ & $618(88.8)$ & + & + & Ataxia \\
\hline 2 & 16 & 827 & $243(29.8)$ & $444(54.8)$ & 783 & $118(16)$ & $575(73.4)$ & + & + & $\begin{array}{l}\text { Malignant carcinoid } \\
\text { syndrome }\end{array}$ \\
\hline 3 & 7 & 1,258 & $112(8.9)$ & $1,022(81.2)$ & 642 & $16(2.5)$ & $551(85.8)$ & & + & \\
\hline 4 & 17 & 1,878 & $373(19.8)$ & $1,373(73.1)$ & 736 & $46(6.2)$ & $601(81.6)$ & & + & Cryptococcal meningitis \\
\hline 5 & 25 & 795 & $162(20.3)$ & $584(73.4)$ & 569 & $78(13.7)$ & $416(73.1)$ & & + & HCV infection \\
\hline 6 & 8 & 1,620 & $78(4.8)$ & $1,429(88.2)$ & 706 & $3(0.4)$ & $680(96.3)$ & + & + & HSV stomatitis \\
\hline
\end{tabular}

A95\% confidence interval range obtained from 40 healthy individuals. Normal values are indicated in bold type. Percentages represent the fraction of the CD4+ or CD 8 T-cell population. Normal values from 25 adults are as follows: CD4 $4^{+} 482-1470$; CD45RO ${ }^{+}$CD4 $^{+} 203-524(23-74)$; CD45RA ${ }^{+}$CD4 $4^{+} 57-608(8-46)$; CD8 ${ }^{+} 180-720$; $\mathrm{CD}_{5 \mathrm{RO}} / \mathrm{CD}^{+} 28-240$ (7-42); $\mathrm{CD}_{5} 5 \mathrm{RA}^{+} / \mathrm{CD}^{+} 50-438$ (13-68). Normal value range for the pediatric control population determined from $15 \mathrm{children}$ (age range $6-16$ years; mean age 9.2 years) is: CD4+ 450-1,434; CD45RO+/CD4+ 162-369 (20.4-59); CD45RA $/$ CD4 $^{+} 171-590(25-61) \cdot$ CD $^{+} 245-859$; CD45RO $/$ CD $^{+} 13-241$ (4-28);

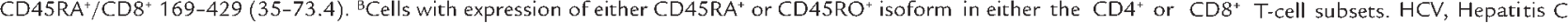
virus; HSV, herpes simplex virus. 
(PHA) at 1:100 (wt/vol), and CD154 trimer (gift of Immunex Corp., Seattle, Washington, USA) at $3.5 \mu \mathrm{g} / \mathrm{ml}$. After $36 \mathrm{~h}$, supernatants were removed. IFN- $\gamma$, IL-12, and TNF- $\alpha$ concentrations were determined by specific ELISA (R\&D Systems Inc., Minneapolis, Minnesota, USA) according to the manufacturer's instructions. CD45RA-enriched PBMCs were prepared by negative selection using anti-CD45RO antibody (UCHL-1) and immunomagnetic beads Dynal Inc. (Lake Success, New York, USA). The procedures followed were in accordance to the manufacturer's instructions and with methods described previously (19). In the resulting population, $\mathrm{CD}^{+} \mathrm{T}$ cells were $>95 \%$ $\mathrm{CD}^{2} \mathrm{RA}^{+}$. In in vitro culture, $10^{6}$ cells were stimulated with OKT3 or with SAC and human IgG at $1 \mu \mathrm{g} / \mathrm{ml}$ (Jackson ImmunoResearch Laboratories Inc., West Grove, Pennsylvania, USA) or SAC with CTLA4-Fc at $1 \mu \mathrm{g} / \mathrm{ml}$ (R\&D Systems Inc.). The cells were then harvested $72 \mathrm{~h}$ later, and two-color flow cytometric analysis was performed by methods described previously (20).

Statistical analysis. Wilcoxon rank-sum test was used to compare measurements between patients and normal volunteers. All $P$ values are two-sided.

\section{Results}

Clinical features of the patients with XHIM. As shown in Table 1, five of the six patients with XHIM who were studied had histories of $P$. carinii infection, an opportunistic infection not commonly associated with other humoral immunodeficiencies. In addition, most of the patients have histories suggesting other opportunistic infections or immune surveillance defects. Patient 1 has cerebellar ataxia of unknown etiology despite intensive investigation. Patient 2 has malignant carcinoid tumor and carcinoid syndrome; 12 months before the study, he had a partial pancreas resection and has since completed five cycles of chemotherapy with cisplatin/etoposide. $\mathrm{He}$ was studied six weeks after the completion of chemotherapy, when he was in remission. Patient 5 has hepatitis $C$ infection presumably acquired from prior infusions of fresh frozen plasma. Patient 6 had recurrent herpes simplex stomatitis requiring maintenance on suppressive therapy with acyclovir. Laboratory evaluations revealed that three of six patients had a lymphocytosis primarily of $\mathrm{CD}^{+} \mathrm{T}$ cells. All six patients were maintained on monthly intravenous immunoglobulin (IVIG) therapy, and four of the six patients were maintained on G-CSF for neutropenia.

CD154 mutations in affected patients. Five of the six patients with XHIM studied have mutations on exon 5 of the extracellular domain (21). Patient 1 has a donor splice site mutation at exon $1 \mathrm{GT} \rightarrow \mathrm{TT}$ (Slater, J.E., unpublished observations); expression of the mutant protein was not detectable by flow cytometry using anti-CD154 antibody (Jain, A., and Strober, W., unpublished observations). Patient 2 has an A insertion between nt424G and nt430G, resulting in a frameshift of the CD154 coding frame; thus, his CD40 ligand gene would be expected to yield a truncated protein consisting of 163 amino acids (14). Patient 3 has an $\mathrm{A} \rightarrow \mathrm{G}$ substitution at $\mathrm{nt} 509$, resulting in a change in the amino acid $\mathrm{Y} \rightarrow \mathrm{C}$ substitution at position 170 (22). Patient 4 has a 6-bp in-frame deletion at nt424-429 that causes the deletion of amino acids $\mathrm{G} \rightarrow \mathrm{L}$ at positions 142 and 143 (23). Patient 5 has $\mathrm{C} \rightarrow \mathrm{A}$ substitution at nt623, resulting in an amino acid substitution $A \rightarrow D$ at position
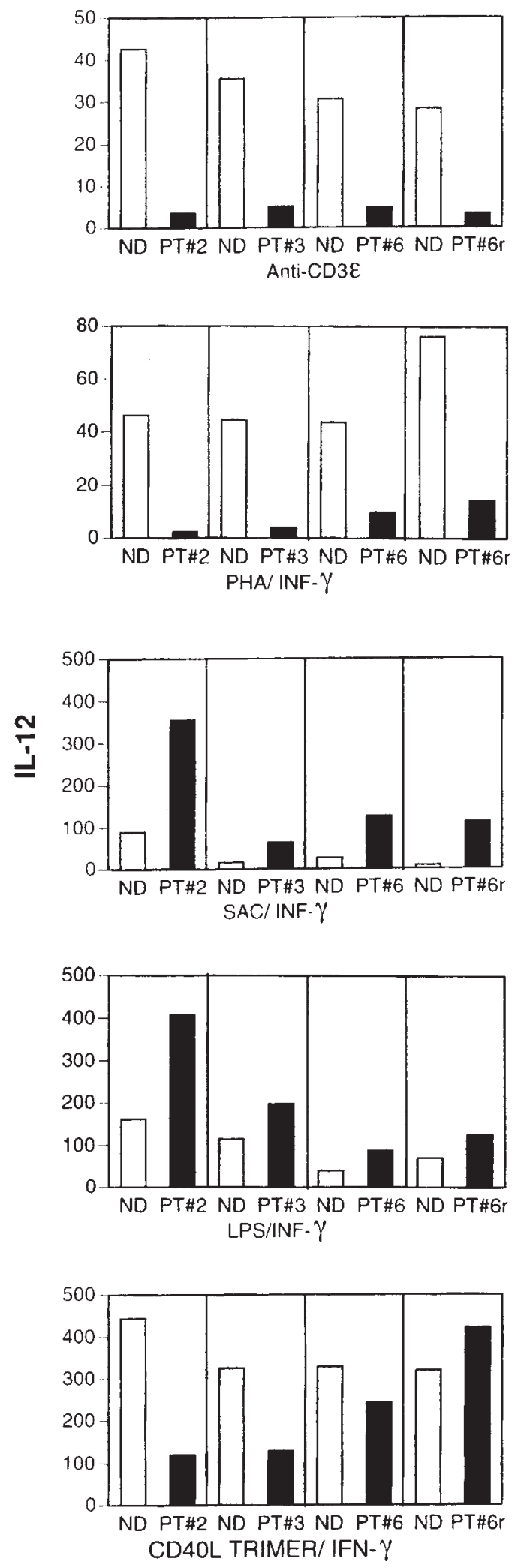

Figure 2

Secretion of IL-12 (pg/ml) obtained from patients with XHIM and from normal volunteers. PBMCs $\left(2 \times 10^{6}\right)$ were stimulated by antiCD3e, PHA/IFN- $\gamma$, LPS/IFN- $\gamma$, SAC/IFN- $\gamma$, or CD 40 L trimer/IFN- $\gamma$. Patient 6 was studied twice. Cytokine measurements were determined at $36 \mathrm{~h}$ by specific ELISA. 
208 (Nelson, D.L., unpublished observations). Patient 6 has a $\mathrm{G} \rightarrow \mathrm{A}$ substitution at nt655, resulting in an amino acid substitution of $\mathrm{G} \rightarrow \mathrm{R}$ at position 219 , and a $\mathrm{C} \rightarrow \mathrm{T}$ substitution at 695 , resulting in a stop codon and a truncated protein of 232 amino acids (15).

APCs from patients with XHIM do not produce IL-12 and produce markedly reduced levels of TNF- $\alpha$ upon stimulation with antigen-activated $T$ cells. Previous studies have shown that activated T cells stimulate APCs to produce cytokines by CD154/CD40 interaction $(24,25)$. Thus, in our initial studies of immune function in patients with XHIM, we determined the capacity of their PBMCs to produce IL12 when stimulated with T-cell activators. To this end, we cultured PBMCs from three patients with XHIM (patient
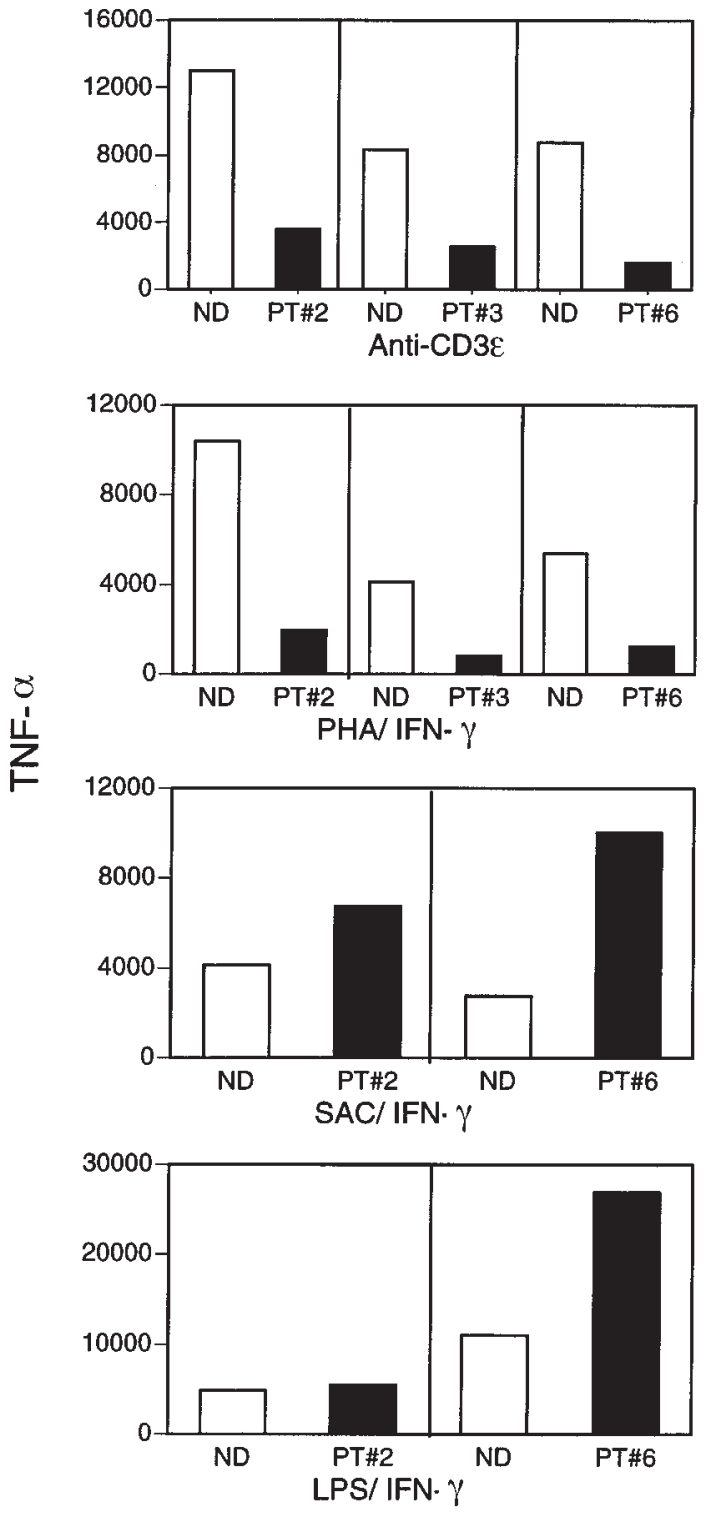

Figure 3

Secretion of TNF- $\alpha(\mathrm{pg} / \mathrm{ml})$ obtained from patients with XHIM and from normal volunteers. PBMCs $\left(2 \times 10^{6}\right)$ were stimulated by anti-CD3 $\varepsilon$, PHA/IFN- $\gamma$, LPS/IFN- $\gamma$, or SAC/IFN- $\gamma$. Cytokine measurements were determined at $36 \mathrm{~h}$ by specific ELISA.
6 was studied twice) and normal volunteers with either PHA/IFN- $\gamma$ or anti-CD3 $\varepsilon$. Activation of T cells with either anti-CD $3 \varepsilon$ or PHA stimulation in patients with XHIM was noted by enlargement of cell size (determined by FACS on forward-/side-scatter dot plot analysis) and increased $\left[{ }^{3} \mathrm{H}\right]$ thymidine incorporation (one study). After 36 h, we measured IL-12 secretion into culture fluid by specific ELISA. Monocytes in PBMCs from the patients with XHIM failed to produce measurable levels of IL-12 in response to either stimulant compared with controls (see Figure 2). This reduced production of IL-12 was not due to an intrinsic inability to synthesize this cytokine, because in patients with XHIM, monocytes in PBMCs cultured with either trimeric CD154/IFN- $\gamma$, LPS/IFN- $\gamma$, or SAC/IFN- $\gamma$ produced, if anything, increased amounts of IL-12. Such increased IL-12 production may in part be due to prior conditioning of the patients' monocytes by exogenous G-CSF, used for treatment of neutropenia.

In further studies, we determined the capacity of monocytes in PBMCs of patients with XHIM to produce TNF- $\alpha$ after stimulation with T-cell activators. Accordingly, supernatants from the culture conditions already described were also tested for TNF- $\alpha$ by specific ELISA. As shown in Figure 3, monocytes in PBMCs from patients with XHIM produced significantly reduced levels of TNF- $\alpha$ compared with those of normal volunteers. Again, the reduced TNF- $\alpha$ production was not due to an inability to produce TNF- $\alpha$, as patients with XHIM produce normal levels of TNF- $\alpha$ when their monocytes in PBMCs are stimulated with LPS/IFN- $\gamma$ or SAC/IFN- $\gamma$. Taken together, these studies demonstrate that monocytes of patients with XHIM are markedly deficient in their capacity to produce cytokines when stimulated by activated T cells, because of the absence of CD154/CD40 interaction.

T cells of patients with XHIM manifest deficient IFN- $\gamma$ production that can be restored with CD154 trimer stimulation. The deficiency in monocyte IL-12 production upon stimulation with activated $\mathrm{T}$ cells in patients with XHIM suggests that cognate interactions between APCs and $\mathrm{T}$ cells would result in reduced IFN- $\gamma$ production $(25,26)$. To explore this possibility, we cultured PBMCs with anti-CD3 or PHA for $36 \mathrm{~h}$ and then measured IFN$\gamma$ secretion into the culture fluid by specific ELISA. As shown in Figure 4, patients with XHIM produce markedly reduced amounts of IFN- $\gamma$ compared with controls. To demonstrate that the reduced IFN- $\gamma$ production was due to the lack of CD154, we stimulated PBMCs from controls and patients with XHIM with anti-CD3 $\varepsilon$ as before, but this time in the presence of CD154 trimer. CD154 trimer restored IFN- $\gamma$ production in the three patients with XHIM who were studied.

Patients with XHIM have a markedly reduced pool of mature $\left(C D 45 R O^{+}\right)$T cells. In humans, antigen priming of T cells is associated with a change in T-cell CD45 isoform expression (27). Naive T cells express the CD45RA isoform, whereas antigen-primed (memory) $\mathrm{T}$ cells express the CD45RO isoform $(28,29)$. Given the occurrence of T-cell priming defects in CD154 knockout mice (30), as well as the evidence of cytokine production deficiency in the patients discussed here, we evaluated the expression of the CD45 isoforms by the T cells of patients with 
XHIM by flow cytometry. As indicated in Figure 5a, all six patients studied had $\mathrm{CD}^{+}{ }^{+} \mathrm{T}$-cell populations containing reduced percentage of cells expressing CD45RO and increased percentage of cells expressing CD45RA. Thus, in five of six patients, the percentage value of $\mathrm{CD}^{+}$ $\mathrm{T}$ cells expressing CD45RO fell below the range determined for normal volunteers, whereas the fifth patient's percentage value fell in the lower limits of the normal range (this patient's CD45RO percentage value may have been transiently elevated because he had recently completed chemotherapy, a procedure known to reduce the naive CD45RA T-cell population; ref. 17). In keeping with these findings, the population of $\mathrm{CD} 4^{+} \mathrm{T}$ cells expressing CD45RO in patients with XHIM was significantly reduced both in absolute number $(P>0.007)$ and in percentage $(P>0.0002)$ when compared with controls. In further studies, we also showed that $\mathrm{CD}^{+} \mathrm{T}$-cell population in patients with XHIM contained a reduced percentage of cells expressing CD45RO $(P>0.002)$ and an increased percentage of cells expressing CD45RA $(P>$ $0.0001)$. Finally, given the fact that CD $45 \mathrm{RO}$ memory cells increase with age (31), and four of six patients were 16 years of age or younger (mean age of 9.3 years), the patient values were also compared with a large agematched control group $(n=15)$ with a mean age of 12.7 years $(P>0.17)$. Patients with XHIM still manifested significantly low CD45RO T-cell values (CD4+: \%CD45RO, $P>0.01$ \% \%D45RA, $P>0.004$; $\mathrm{CD}^{+}$: \%CD45RO, $P>$ $0.04, \%$ CD 45RA, $P>0.003)$. Of interest, analysis of two obligate carriers of the CD154 gene mutation indicated that carriers also had reduced numbers of $\mathrm{T}$ cells with exclusive expression of CD45RO. In studies of two mothers of patients with XHIM, the percentages of $\mathrm{CD}^{+}$ $\mathrm{T}$ cells expressing CD $45 \mathrm{RO}$ were $11 \%$ and $20 \%$, respectively, both values well below the $95 \%$ confidence interval for normal subjects (Jain, A., and Strober, W., unpublished observations). These studies demonstrate that patients with XHIM have a diminished capacity to prime $T$ cells and induce a mature T-cell phenotype.

Inbibition of the CD28/B7 interaction blocks T-cell conversion from $C D 45 R A^{+}$to $C D 45 R O^{+}$. Previous studies have shown that in vitro primary stimulation of $\mathrm{T}$ cells by PHA or anti-CD $3 \varepsilon$ (32) alone induces transition of naive $\mathrm{CD}^{+} / \mathrm{CD} 45 \mathrm{RA}^{+} \mathrm{T}$ cells into the mature $\mathrm{CD} 45 \mathrm{RO}^{+}$phenotype; indeed, we confirmed this finding in two normal volunteers and one patient with XHIM (Jain, A., and Strober, W., unpublished observations). However, the marked reduction in the $\mathrm{CD}_{45} \mathrm{RO}^{+} \mathrm{T}$-cell population in patients with XHIM suggests that in vivo CD154 provides an advantage in $\mathrm{T}$-cell maturation and that engagement of the antigen receptor alone by peptide/MHC is usually not adequate for the generation of mature $\mathrm{T}$ cells. One possible explanation for this discrepancy is that the generation of CD $45 \mathrm{RO}^{+} \mathrm{T}$ cells in vivo normally requires costimulation of $\mathrm{T}$ cells by $\mathrm{B} 7$ (CD80/86)/CD28 interaction and that the reduction in $\mathrm{CD}^{4} \mathrm{RO}^{+} \mathrm{T}$ cells in patients with XHIM is due the absence of CD154/CD40 interaction and the subsequent failure to upregulate CD80/86 on APCs (33-35). To investigate this possibility, we first determined whether CD80/86 regulates the conversion of normal naive CD45RA ${ }^{+} \mathrm{T}$ cells to a mature $\mathrm{CD}_{45 \mathrm{RO}^{+}}$cells. In these studies, we stimulated normal donor PBMCs (depleted of CD45RO ${ }^{+}$cells) with SAC, a potent APC activator. As shown in Figure 6, when macrophages in PBMCs are stimulated with SAC, the $\mathrm{CD}^{+}{ }^{+} \mathrm{T}$ cells transition from CD45RA+-expressing cells to $\mathrm{CD}^{+} 4 \mathrm{RO}^{+}-$ expressing cells during the three days of culture. In contrast, when PBMCs are stimulated in the same way in the presence of CTLA4-Fc, the cells fail to undergo such a transition. We next determined whether patients with XHIM manifest a defect in the upregulation of B7 molecules. In these studies, we found that, unlike those from normal volunteers, B cells in PBMCs from patients with XHIM fail to induce CD86 surface expression when stimulated with PHA. Furthermore, CD86 expression on B cells can be restored when PBMCs are stimulated with PHA and CD154 trimer (Jain, A., and Strober, W., unpublished observations). Together, these findings confirm the importance of costimulatory molecules normally induced by CD154 in the maturation of T cells into cells expressing CD45RO. As such, they provide a compelling explanation for the reduced induction of mature memory cells in patients with XHIM.
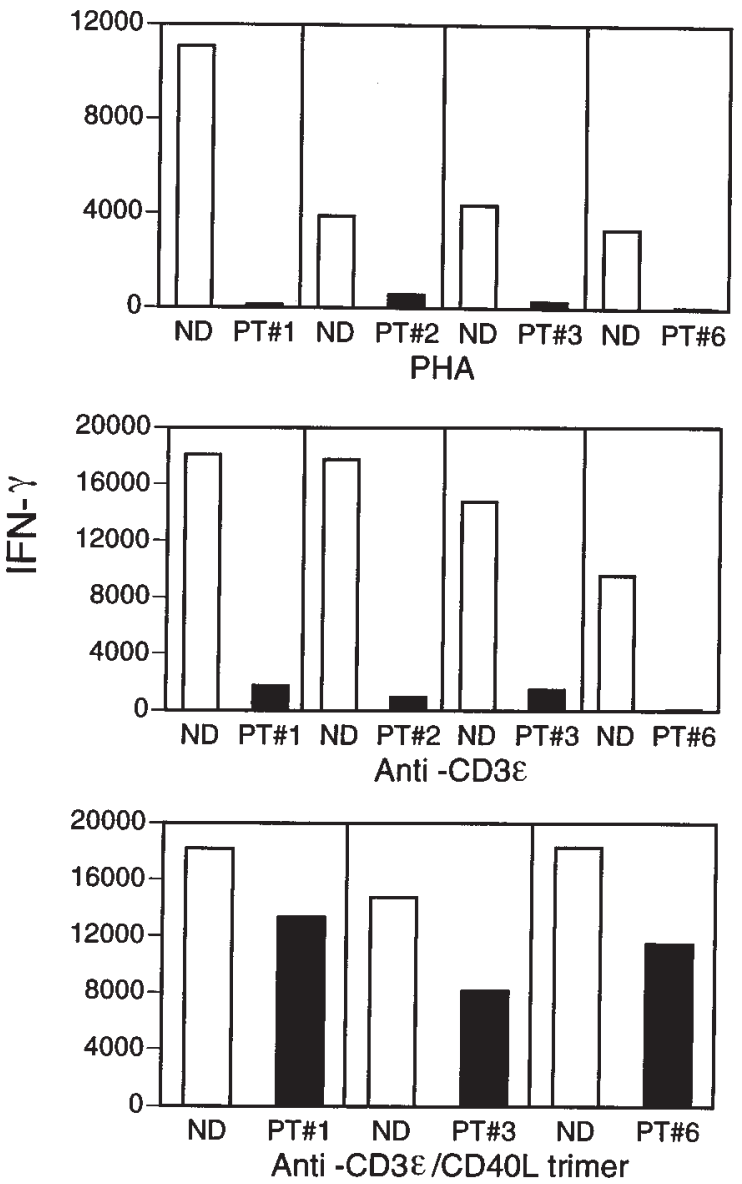

Figure 4

Secretion of IFN $-\gamma(\mathrm{pg} / \mathrm{ml})$ obtained from patients with XHIM and from normal volunteers. PBMCs $\left(2 \times 10^{6}\right)$ were stimulated by anti-CD3E, PHA, or anti-CD3\&/CD40L trimer. Cytokine measurements were determined at $36 \mathrm{~h}$ by specific ELISA. 
a

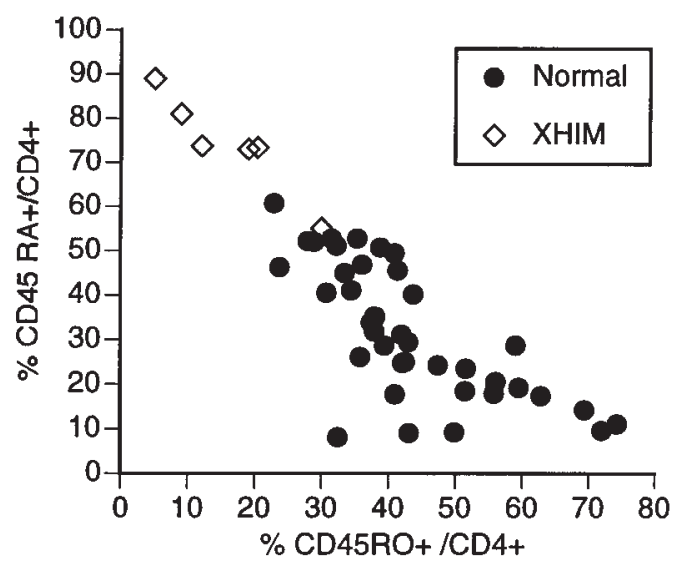

b

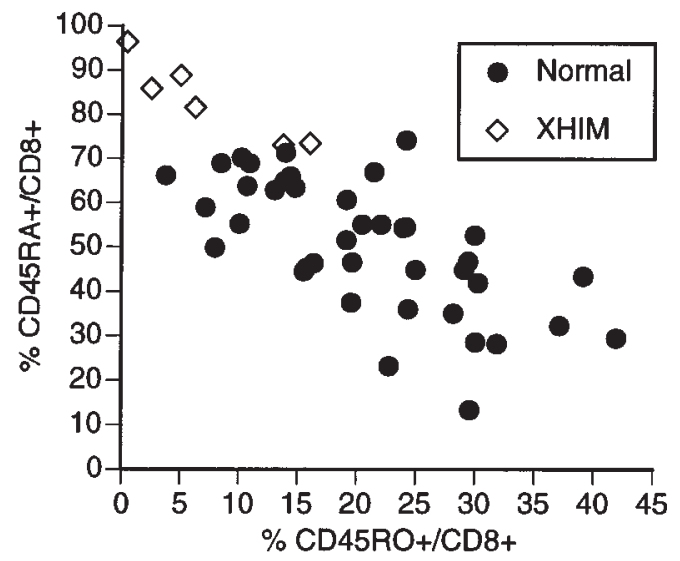

Figure 5

Percentage of cells with exclusive expression of CD45RA or CD45RO in the CD4 ${ }^{+}$and $C D 8^{+}$T-cell subsets of six patients with XHIM and from 40 controls. (a) Patients with XHIM have a marked reduction in the percentage of CD4 ${ }^{+} \mathrm{T}$ cells with expression of CD45RO $(P<0.0002)$ and an increase in the percentage of CD4 ${ }^{+} \mathrm{T}$ cells with expression of CD45RA $(P<0.0001)$. (b) Patients with XHIM also have a significant reduction in the percentage of CD8 ${ }^{+}$T cells with expression of CD45RO $(P<0.002)$ and an increase in CD8 ${ }^{+}$T cells expressing CD45RA $(P<0.0001)$.

\section{Discussion}

In the present study, we demonstrate that activated $\mathrm{T}$ cells in patients with XHIM fail to produce meaningful levels of IFN- $\gamma$, fail to induce APC secretion of IL-12, and induce markedly reduced secretion of TNF- $\alpha$. In addition, we report that patients with XHIM have a defect in postthymic maturation of T cells, manifested by a greatly diminished capacity to generate mature (memory) CD45RO ${ }^{+} \mathrm{T}$ cells of both the CD4 and CD8 subsets. These abnormalities are directly attributable to deficient CD154 signaling and provide a basis for the susceptibility of patients with XHIM to opportunistic infection.

Cell-surface interaction between CD154 on $\mathrm{CD}^{+}{ }^{+} \mathrm{T}$ cells and CD40 on B cells and other APCs is now well recognized as a central requirement for most types of the host immune response. Initially, the importance of CD154 was noted in relation to B-cell isotype switching (36-38). B cells interact with antigen by means of their immunoglobulin receptor, internalize antigen, and then present processed antigen to $\mathrm{CD}^{+} \mathrm{T}$ cells; the $\mathrm{CD}^{+} \mathrm{T}$ cells stimulated in this way express surface CD154 and then backstimulate the B cells via CD40 to undergo isotype switching and terminal B-cell differentiation. Because IgM secretion can occur in the absence of CD154 signaling, these T-cell/B-cell interactions explain why ineffective CD154/CD40 interaction leads to low levels of IgG, IgA, and IgE, and to normal-to-elevated levels of IgM, both in patients with XHIM and in CD154 knockout mice. Recently, normal levels of CD27 $/ \mathrm{IgD}^{+}$ $\mathrm{B}$ cells and an absence of $\mathrm{CD}^{2} 7^{+} / \mathrm{IgD}^{-} \mathrm{B}$ cells, the latter a more mature B-cell form, have been shown in patients with XHIM (39). This finding is analogous to our finding in T cells and presumably relates to the same defect of CD154/CD40 interaction.

To expand this latter point, it has recently become apparent that CD154 signaling also plays a key role in Tcell differentiation. The locus of interaction, in this case, is between dendritic cells or monocytes and T cells. Acti- vated $\mathrm{T}$ cells expressing CD154 interact with CD40 on APCs and induce upregulation of CD80/86 and IL-12 secretion. IL-12 secretion by APCs leads to the differentiation of naive T cells into Th1 cells. The importance of this interaction in vivo has been shown in a Th1 T cell-dependent murine colitis model (TNBS-colitis), in which it was observed that its blockade by anti-CD154 antibody prevented TNBS-induced inflammation of the colon (40). Similarly, as already noted, CD154 knockout mice infected with Leishmania have T cells that fail to produce INF- $\gamma$ and monocytes that fail to produce IL-12 (13). Finally, it has recently been shown that the interaction between CD154 on antigen-specific $\mathrm{CD}^{+} \mathrm{T}$ cells and CD40 on dendritic cells is also critical to the development of CD8 ${ }^{+}$cytolytic T cells (CTLs) (41-43). This was demonstrated by in vitro studies in which it was shown that interference with this interaction inhibits the maturation of antigen-specific $\mathrm{CD}^{+} \mathrm{T}$ cells into effector CTLs.

The role of CD154/CD40 interaction in various aspects of T-cell function provides a basis for the finding that patients with XHIM manifest diverse T-cell defects. Perhaps the most profound of these defects is the inability of activated $T$ cells to induce cytokine production by APCs. In the present study, we demonstrate that although patients with XHIM have the capacity to produce IL-12 and TNF- $\alpha$ when their PBMCs are stimulated with SAC/IFN- $\gamma$ or LPS/IFN- $\gamma$, they fail to produce IL12 and produce greatly reduced levels of TNF- $\alpha$ when their PBMCs are stimulated by anti-CD3 $\varepsilon$ or PHA/IFN$\gamma$. These results imply that patients with XHIM produce IL- 12 and TNF- $\alpha$ by direct stimulation of monocytes by certain microbes but manifest defects when such cytokine production is elicited by antigen-activated $\mathrm{CD}^{+} \mathrm{T}$ cells expressing CD154. In turn, APC stimulation defects have a major effect on T-cell cytokine production. Thus, PBMCs stimulated by the T-cell activators PHA and anti-CD3e normally produce large amounts of IFN- $\gamma$ in normal individuals; similar stimu- 
lation of PBMCs in patients with XHIM is associated with greatly reduced IFN- $\gamma$ production.

A second and interlocking abnormality of T-cell function in patients with XHIM relates to their defective Tcell priming. Thus, patients with XHIM have a markedly reduced percentage of antigen-primed $\mathrm{T}$ cells, as defined by the surface CD45RO expression by both $\mathrm{CD}^{+}$and $\mathrm{CD}^{+} \mathrm{T}$ cells. The relationship of this abnormality to defective CD154 expression and signaling was indicated by two additional findings. First, we showed that two obligate carriers of the CD154 gene mutation also manifest reduced numbers of mature $\mathrm{CD}^{+} \mathrm{T}$ cells. Given the random nature of X-chromosome inactivation, these female carriers may have a large portion of the circulating $\mathrm{CD}^{+}{ }^{+} \mathrm{T}$ cells with nonfunctional CD154 and, as a result, manifest defects in post-thymic maturation of $\mathrm{T}$ cells analogous to their male offspring. Second, we demonstrated that isoform switching from CD45RA to CD45RO on T cells is blocked in vitro by CTLA4-Fc (an inhibitor of CD28 interaction with CD80/86) and that patients with XHIM manifest defective upregulation of CD86 due to the lack of CD154 signaling. These finding suggest that the reduced CD45RO expression in patients with XHIM is a direct manifestation of the core defect in CD154 expression.

Studies of immune responses in patients with XHIM, as well as their clinical course, correlate well with their immunological findings. Thus, the limited number of studies of in vitro $T$ cell-proliferative responses to specific antigens have revealed either normal responses to tetanus toxoid or lectins or reduced responses to various antigens, which generally are corrected with booster immunization $(11,44,45)$. In this regard, two of the three patients tested in our series demonstrate normal delayed-type skin test responses without booster immunization (one to tetanus, one to candida and mumps). These observations demonstrate that CD154-independ- ent mechanisms do exist for T-cell activation and differentiation in humans. Clinically, this partial preservation of T-cell immunity accounts for the fact that the infectious complications in patients with XHIM are not as grave as those seen in severe combined immunodeficiency. Nevertheless, despite alternative routes to T-cell effector function, patients with XHIM routinely suffer from fulminant viral hepatitis, Cryptosporidium infection, and $P$. carinii pneumonia (11). In addition, reports of hepatobiliary cancer, carcinoid tumor, and other neoplasms in patients with XHIM suggest defective immune surveillance $(11,14,46)$.

The immune defects in patients with XHIM described here appear to have consequences early in life. In the only large retrospective study of 56 patients, the KaplanMeier survival rate was $20 \%$ by the age of 25 years despite IVIG therapy, with the vast majority of deaths occurring in the second decade of life (11). Such a high mortality rate has not been reported in other immunodeficiencies, such as Bruton's agammaglobulinemia, in which the humoral immune abnormality is controlled by IVIG treatment. Because defective CD154 signaling and the subsequent defects of T-cell effector function are a constant feature of XHIM, we speculate that the increased mortality in patients with XHIM in the second decade of life is due to their defect in the post-thymic maturation of antigen-specific T cells. This view is based on the fact that after the first decade of life, the host cannot expand his or her repertoire of antigen-specific T cells because of thymic involution and the failure of post-thymic $T$ cells to undergo somatic mutation. As a result, the host becomes more dependent on the preexisting antigenprimed population of $T$ cells for defense against infectious disease and immune surveillance. Thus, the contracted population of antigen-primed $T$ cells, caused by a failure of post-thymic maturation, renders these patients particularly susceptible to opportunistic infection and cancer early in life.
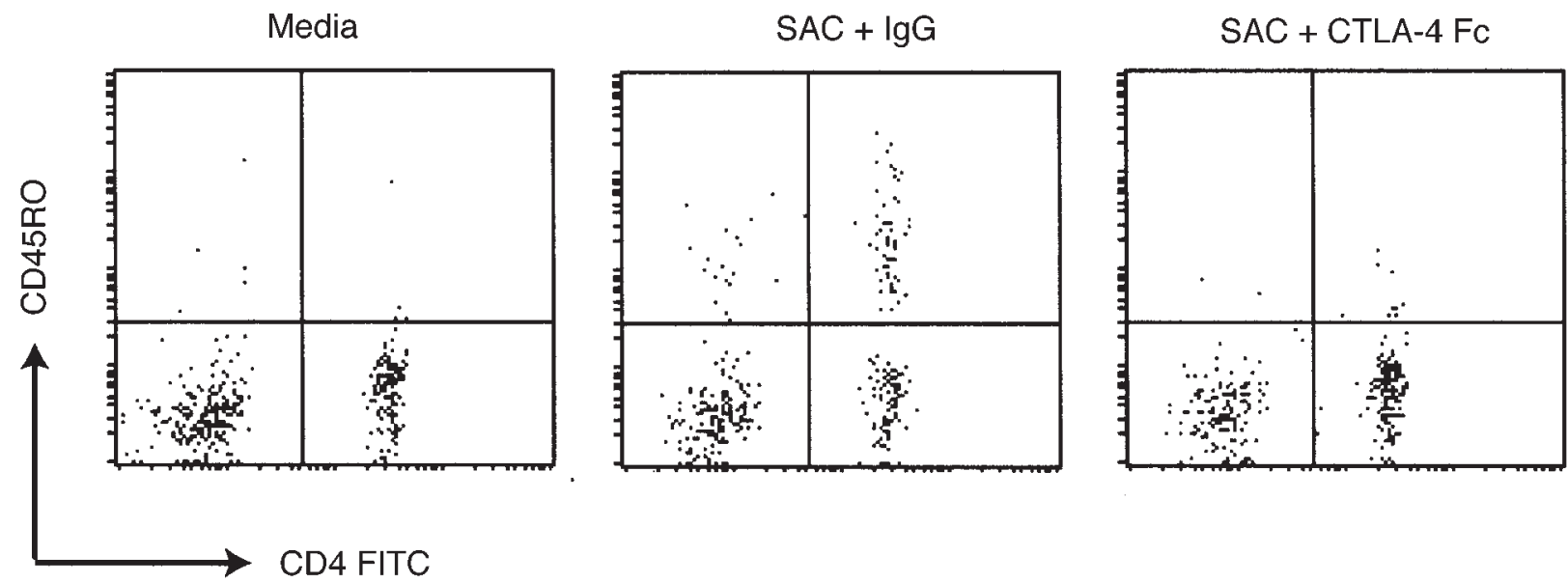

Figure 6

Inhibition of CD28/B7 interaction blocks T-cell conversion from CD45RA ${ }^{+}$to CD45RO ${ }^{+}$. PBMCs from a normal individual were depleted of CD45RO ${ }^{+}$ expressing cells. Cells were cultured at $10^{6}$ cells $/ \mathrm{ml}$ in media alone, or stimulated with SAC and control human IgG or SAC with CTLA4-Fc. Cells were harvested $60 \mathrm{~h}$ later and stained with anti-CD4 FITC and anti-CD45RO phycoerythrin, and two-color analysis was carried out using the same gate in all conditions. These data are representative of two normal donor samples. 
An important therapeutic possibility that arises from these studies is that the poor Th1 T-cell responses in patients with XHIM may be ameliorated by supplemental IFN- $\gamma$ therapy (47). Studies in patients with chronic granulomatous disease have demonstrated IFN- $\gamma$ has limited side effects and is associated with improved host defense. Another rational approach to therapy would be CD154 administration; this form of replacement therapy is becoming feasible with the availability of recombinant CD154.

\section{Acknowledgments}

We thank Thomas Fleisher and Margaret Brown for immunological evaluations, and Hans Ochs, Luigi Notarangelo, and Lynda Schneider for assistance with sequencing information on individual patients.

1. Callard, R.E., Armitage, R.J., Fanslow, W.C., and Spriggs, M.K. 1993. CD40 ligand and its role in X-linked hyper-IgM syndrome. Immunol. Today. 14:559-564.

2. Notarangelo, L.D., Duse, M., and Ugazio, A.G. 1992. Immunodeficiency with hyper-IgM (HIM). Immunodefic. Rev. 3:101-122.

3. Fuleihan, R., et al. 1993. Defective expression of CD40 ligand in X chromosome-linked immunoglobulin deficiency with normal or elevated IgM. Proc. Natl. Acad. Sci. USA. 90:2170-2173.

4. DiSanto, J.P., Bonnefoy, J.Y., Gauchat, J.F., Fischer, A., and deSaint Basile, G. 1993. CD40 ligand mutations in X-linked immunodeficiency with hyper-IgM. Nature. 361:541-543.

5. Allen, R.C., et al. 1993. CD40 ligand gene defects responsible for X-linked hyper-IgM syndrome. Science. 259:990-993.

6. Aruffo, A., et al. 1993. The CD40 ligand, gp39, is defective in activated T cells from patients with X-linked hyper-IgM syndrome. Cell. 72:291-300.

7. Korthauer, U., et al. 1993. Defective expression of T cell CD40 ligand causes X-linked immunodeficiency with Hyper-IgM. Nature. 361:539-541.

8. Xu, J., et al. 1994. Mice deficient for the CD40 ligand. Immunity. 1:423-431.

9. Han, S., et al. 1995. Cellular interaction in germinal centers. Roles of CD40 ligand and B7-2 in established germinal centers. J. Immunol. 155:556-567.

10. Renshaw, B.R., et al. 1994. Humoral immune responses in CD40 liganddeficient mice. J. Exp. Med. 180:1189-1900.

11. Levy, J., et al. 1997. Clinical spectrum of X-linked hyper-IgM syndrome. J. Pediatr. 131:47-54

12. Soong, L., et al. 1996. Disruption of CD40-CD40 ligand interaction results in an enhanced susceptibility to Leishmania amazonensis infection. Immunity. 4:263-273.

13. Campbell, K.A., et al. 1996. CD40 ligand is required for protective cellmediated immunity to Leishmania major. Immunity. 3:283-289.

14. Seyama, K., et al. 1998. Mutations of the CD40 ligand gene and its effect on CD40 ligand expression in patients with X-linked hyper IgM syndrome. Blood. 7:2421-2434.

15. Grammer, A.C., et al. 1995. The CD40 ligand expressed by human B cells costimulates B cell responses. J. Immunol. 154:4996-5010.

16. Ramesh, N., et al. 1993. Deletions in the ligand for CD40 in X-linked immunoglobulin deficiency with normal to elevated IgM (HIGMX-1). Int. Immunol. 5:769-773.

17. Mackall, C.L., et al. 1995. Age, thymopoiesis, and CD4+ T-lymphocyte regeneration after intensive chemotherapy. N. Engl. J. Med. 332:143-149.

18. Kanof, M.E. 1991. Preparation of human mononuclear cell populations and subpopulations. In Current protocols in immunology. J.E. Coligan, A.M. Kruisebeek, D.H. Margulies, E.M. Shevach, and W. Strober, editors. Greene Publishing and Wiley Interscience. New York, NY. 7.1.2-7.1.3.

19. Fuss, I.J., et al. 1996. Disparate CD4+ lamina propia (LP) lymphocytes secretion profiles in inflammatory bowel disease: Crohn's disease LP cells manifest increased secretion of IFN-gamma, whereas ulcerative colitis LP manifest increased secretion of IL-5. J. Immunol. 157:1261-1270.

20. Holmes, K., and Fowlkes, B.J. 1991. Preparation of cells and reagents for flow cytometry. In Current protocols in immunology. J.E. Coligan, A.M.
Kruisebeek, D.H. Margulies, E.M. Shevach, and W. Strober, editors. Greene Publishing and Wiley Interscience. New York, NY. 5.3.1-5.3.5. 21. Villa, A., et al. 1994. Organization of the human CD40L gene: implications of molecular defects in X chromosome-linked hyper-IgM syndrome and prenatal diagnosis. Proc. Natl. Acad. Sci. USA. 91:2110-2114.

22. Atkinson, T.P., et al. 1998. Leukocyte transfusion-associated granulocyte responses in a patient with X-linked hyper-IgM syndrome. J. Clin. Immunol. 18:430-439.

23. Chu, Y.W., et al. 1995. Somatic mutation of human immunoglobulin V genes in the X-linked hyper IgM syndrome. J. Clin. Invest. 95:1389-1393.

24. Grewal, I.S., and Flavell, R.A. 1988. CD40 and CD154 in cell mediated immunity. Annu. Rev. Immunol. 16:111-135.

25. Shu, U., et al. 1995. Activated T cells induce interleukin-12 production by monocytes via CD40-CD40 ligand interaction. Eur. J. Immunol. 25:1125-1128.

26. Trinchieri, G. 1988. Proinflammatory and immunoregulatory functions of interleukin-12. Int. Rev. Immunol. 16:365-396.

27. Mackay, C.R. 1993. Homing of naive, memory and effector lymphocytes. Curr. Opin. Immunol. 5:423-427.

28. Pilarski, L.M., Gillitzer, R., Zola, H., Shortman, K., and Scollay, R. 1989. Definition of the thymic generation lineage by selective expression of high molecular weight isoforms of CD45 (T200). Eur. J. Immunol. 19:589-597.

29. Fujii, Y., Okumura, M., Inada, K., Nakahara, K., Matusda, H. 1992. CD45 isoform expression during $\mathrm{T}$ cell development in the thymus. Eur. J. Immunol. 22:1843-1850.

30. Grewal, I.S., Xu, J., and Flavell, R.A. 1995. Impairment of antigen-specific T-cell priming in mice lacking CD40 ligand. Nature. 378:617-620.

31. Erkeller-Yuksel, F.M., et al. 1992. Age related changes in human blood lymphocytes subpopulations. J. Pediatr. 120:216-222.

32. Serra, H.M., Krowka, J.F., Ledbetter, J.A., and Pilarski, L.M. 1988. Loss of CD45R(Lp220) represents a post-thymic T cell differentiation event. J. Immunol. 140:1435-1441.

33. Cella, M., et al. 1996. Ligation of CD40 on dendritic cells triggers production of high levels of interleukin-12 and enhances $\mathrm{T}$ cell stimulatory capacity: T-T help via APC activation. J. Exp. Med. 184:747-752.

34. Caux, C., et al. 1994. Activation of human dendritic cells through CD40 cross-linking. J. Exp. Med. 180:1263-1272.

35. Kennedy, M.K., et al. 1994. Induction of B cell costimulatory function by recombinant murine CD40 ligand. Eur. J. Immunol. 24:116-123.

36. Kawabe, T., et al. 1994. The immune responses in CD40-deficient mice: impaired immunoglobulin class switching and germinal center formation. Immunity. 1:167-178.

37. Defrance, T.B., et al. 1992. Interleukin 10 and transforming growth factor beta cooperate to induce anti-CD40-activated naive human B cells to secrete immunoglobulin A. J. Exp. Med. 175:671-682.

38. Gascan, H., Gauchat, J.F., Aversa, G., van Vlasselaer, P., and de Vries, J.E. 1991. Anti-CD40 monoclonal antibodies or CD4+ T cell clones and IL4 induce IgG4 and IgE switching in purified human B cells via different signaling pathways. J. Immunol. 147:8-13.

39. Agematsu, K., et al. 1998. Absence of IgD-CD27(+) memory B cell population in X-linked hyper-IgM syndrome. J. Clin. Invest. 102:853-860.

40. Stuber, E., Strober, W., and Neurath, M. 1996. Blocking the CD40LCD40 interaction in vivo specifically prevents the priming of T helper 1 cells through the inhibition of interleukin 12 secretion. J. Exp. Med. 183:693-698.

41. Schoenberger, S.P., Toes, R.E., van der Voort, E.I., Offringa, R., and Melief, C.J. 1998. T-cell help for cytotoxic T lymphocytes is mediated by CD40-CD40L interactions. Nature. 393:480-483.

42. Bennett, S.R., et al. 1998. Help for cytotoxic-T-cell responses is mediated by CD40 signalling. Nature. 393:478-480.

43. Ridge, J.P., Di Rosa, F., and Matzinger, P. 1988. A conditioned dendritic cell can be a temporal bridge between a CD4+ T- helper and a T-killer cell. Nature. 393:474-478.

44. Ameratunga, R., et al. 1997. Defective antigen-induced lymphocyte proliferation in the X-linked hyper-IgM syndrome. J. Pediatr. 131:147-150.

45. Geha, R.H., et al. 1979. Hyperimmunoglobulin M immunodeficiency. J. Clin. Invest. 64:385-391.

46. Hayward, A.R., et al. 1997. Cholangiopathy and tumors of the pancreas, liver, and biliary tree in boys with X-linked immunodeficiency with hyper-IgM. J. Immunol. 158:977-983.

47. The International Chronic Granulomatous Disease Cooperative Study Group. 1991. A controlled trial of interferon gamma to prevent infection in chronic granulomatous disease. N. Engl. J. Med. 324:509-516. 